\title{
The Dangers of Reading Globally
}

\author{
By Kathy G. Short
}

This article is based on a keynote delivered at the $36^{\text {th }}$ IBBY International Congress in Athens, Greece on August 31, 2018. IBBY members are committed to the potentials offered by global literature for opening minds to multiple ways of living in the world and creating intercultural understanding. Asking readers to read outside their comfort zones, however, can instead hold danger and perpetuate stereotypes and misunderstandings. This article proposes that we can address these dangers through acting on our social responsibilities as bookmakers, readers, and educators to balance individual voice with group responsibility and to determine if our actions could cause harm to readers' understandings of a culture.

An examination of the dangers of reading globally may seem contradictory in a journal whose mission emphasizes the transformative potentials of global literature. Indeed, my experiences with teachers and children around global literature provide compelling evidence that reading globally expands readers' views and encourages the development of empathy and openmindedness toward cultural ways of thinking that differ from their own. What is often overlooked, however, is that asking readers to read outside their comfort zones holds danger as well as possibility and can actually establish misunderstandings and stereotypes. Only by acknowledging these dangers can the possibilities of global literature be realized.

These possibilities are grounded in story as a primary act of mind, as the way in which we bring meaning to our experiences and make sense of the chaos of daily life (Rosen). We create stories in our minds in order to be able to understand our experiences. Stories are thus what make us human - the nature of a life is that it's a story. Our views of the world develop as a web of interconnected stories that we keep adding to and rearranging in our minds (Short, “Story”).

This understanding of story as world-making underlies the potential of reading globally, especially in encouraging narrative imagination so that readers enter story worlds to experience 
how people live, feel, and think around the world. Through literature, readers immerse themselves into these story worlds, providing experiences that go beyond surface-level tourist information to deeper cultural values and beliefs. As readers engage with characters in these story worlds, they develop emotional connections and empathy as well as knowledge about a global culture. They learn from, not merely tolerate, those whose views and ways of living differ from their own. They also come to know their own home cultures better through exploring worlds beyond their homes. These understandings grow out of recognizing the common values they share with those living in other cultural communities as well as the unique differences that distinguish each culture. Experiences with global literature can encourage a stance of reflective openness to how people view themselves, not just how we view them.

These tremendous potentials, however, must be balanced with understanding the dangers of reading globally and exploring how to address those dangers through our social responsibilities as bookmakers, readers, and educators. Social responsibility is a business theory for a system of ethics, in which decisions and actions are ethically considered to determine if an action or decision causes harm to society or to the environment, instead of only considering financial gain (Chandler).

Louise Rosenblatt extends this concept to readers, arguing that responsibility as a reader means that people have the right to their own individual voices, but that right needs to be balanced with a consideration of the consequences for others in the community and the world and of the need for space to hear those voices. Building on Rosenblatt's theories, Suzanne Choo argues that literature supports readers in becoming ethical cosmopolitans, who use imagination to critically engage in a stance of hospitable openness to others. Literature thus functions as a tool that allows readers to access the thinking and beliefs of another person or community, 
becoming an entry for "rich dialogic inquiry to address how one can live fully in relation to diverse others in the world" ("Globalizing" 338). This article builds on this idea, to explore the responsibilities of bookmakers, readers, and educators in relation to global literature.

\section{The Social Responsibility of Bookmakers}

Many articles critique authors and texts in relation to accuracy and authenticity. Moving to a focus on bookmakers recognizes that authors do not act alone but are part of a team that includes the author, illustrator, translator, agent, editor, and publishing team who work together in creating a book. Their work as a team includes the responsibility to research details of everyday life and language for a culture, understand the core beliefs and values of that culture, and explore the published books on that culture to determine the types of representations currently available. In particular, their social responsibility involves considering how to balance individual voice and creativity of expression within a book with the social good of society, both locally and globally, so that a book does not do harm to a global culture.

The enactment of this responsibility is influenced by whether a book is global or international. Global literature refers to any book set in a global context outside the reader's own location, and so there are major variations in the cultural locations of bookmaking teams for these books, as connected to the cultures in the books they create. One type of global literature is international literature, books written and published in a country by bookmakers who are insiders to that culture and then translated and distributed to readers in other cultures.

Within that social responsibility, bookmakers consider accuracy in the details of everyday life and language. That accuracy can often appear to be insignificant details to those outside a culture, such as inaccurately adding an accent mark to mole in Caroline McAlister's Holy Molé! 
(2006) or confusing Chinese and Korean traditions in Helen Recorvitz's Yoon and the Jade Bracelet (2008). When those inaccuracies occur within a book about your own culture, however, you feel a personal sense of violation and lack of respect for your culture by those who created the book.

Authenticity goes beyond details to the core values at the heart of a culture. Although there are always multiple values and ways of living within a culture, authenticity focuses on believability - whether a character acts or thinks in ways that are viewed as possible by insiders of a culture (Fox and Short). For example, books written by Western bookmaking teams that depict Muslim females who struggle to liberate themselves from familial or societal restrictions often do so through actions reflecting a Western lens of feminism, rather than Muslim traditions. An outsider view is imposed on these characters that is in opposition to the core beliefs of their culture, indicating a lack of knowledge of Muslim feminism by bookmakers.

Representation refers to the relationship of an individual book to images of a specific global culture within a collection of books and to the images broadly available in society. A book may be accurate and authentic but still be problematic because of how that book relates to other published books, a distinction that causes tension for bookmakers. Issues may arise, for example, when few books exist about a specific culture, resulting in one or two books being viewed as representative of an entire culture. Or a theme or image may be overrepresented, and so another book with the same image contributes to existing misconceptions. In the United States, picturebooks about countries in the Middle East overflow with images of camels and sand, ignoring the range of landscapes within this region, while books on Ireland primarily focus on either the potato famine or leprechauns. 
Another representational issue is power relationships and who is shown as solving a problem. Until recently, books on new immigrants to the United States disproportionately showed a white child stepping in to "save" a child of color by teaching him or her to speak English.

In the global market, representation is an issue due to the domination of books from English-speaking countries and Western Europe in decisions about what books are translated and made available around the world. This domination results in a low number of translated books published in the United States from other countries (only $2 \%$ to $4 \%$ annually) and high numbers of translated books from the United States and United Kingdom in African and Latin American countries (often as high as $80 \%$ to $90 \%$ ). In the United States, historical fiction and traditional literature are overrepresented in global books, with very few contemporary depictions, leading to misconceptions of global cultures as set back in time. In addition, many global books are set in rural areas and small villages, with few depictions of urban cities, a misrepresentation of the populations of these cultures (Short, "What's Trending” 294).

An example of a book that is accurate and authentic but problematic representationally is Mirror (2010), a wordless book by Jeanne Baker that is praised for visually stunning collages and a message of global interdependence. The book sets up a parallel comparison of a day in the life of two families, one in a remote rural area of Morocco and the other in urban Sydney, Australia. This comparison is unfair and perpetuates the hierarchy of modern Western nations, in contrast to poverty and traditional ways of living in African countries. A comparison of Sydney with Casablanca or of the remote Outback of Australia with rural Morocco would provide a fairer comparison. The audience and perspective of this book are white and Western, as with other books that make comparisons in which the privileged bodies are white and those in poverty 
are people of color, as in A Country Far Away (2012) by Nigel Gray and Same, Same but Different (2011) by Jenny Sue Kostecki-Shaw.

The danger of misleading representations was evident in a classroom in Tucson, Arizona, where eleven-year-olds read novels set in China. These novels were historical fiction, primarily set during the Cultural Revolution, because those were the only novels we could locate. As students met in literature circles, the teacher and I heard many negative comments about abuse, sexism, and violence, and realized students assumed these novels reflected life in China today. We took action to bring in informational materials on modern life in China, and asked students to compare life in the historical and contemporary United States to provide a perspective on change over time to counter the stereotypes we had unintentionally established.

These issues of accuracy, authenticity, and representation can establish stereotypes through global books, instead of opening minds to diversity in the world. When readers see a person or event as one thing over and over, they come to see that person or event in a limited way. Chimamanda Adichie argues that people can be reduced to a single commonplace narrative of who we think they are, rather than who they actually are. Rudine Sims Bishop points out that readers need books that are windows into the lives of others as well as mirrors for their own lives. Readers, however, need windows into many rooms in order to understand a culture. Bookmakers need to be aware of which windows are already plentiful and easy to see through, which are boarded up and difficult to locate, and which windows cannot be found in books on particular global cultures. This responsibility and awareness, however, goes beyond bookmakers to readers as well.

\section{Social Responsibility of Readers}


Discussions about the responsibility of bookmakers and critical analyses of global texts must be balanced with a corresponding focus on readers. Holly Johnson argues that readers have a social responsibility to evaluate the extent to which each reader shares a cultural match or mismatch with a book. Socially responsible readers remain open to books that depict cultural ways of living that are unfamiliar and so may cause discomfort. These readers try to learn from perspectives that differ from their own by focusing on difference and what they can learn from difference, rather than only searching for connection. Choo notes that socially responsible readers also acknowledge that texts create possible worlds that may be unfamiliar to them personally, but those worlds and cultures exist and hold value (Reading 140).

Cultural mismatches between readers and books occur at many levels. A mismatch was evident when Natali, an eleven-year-old in Tucson, commented that an Arabic picturebook opened backwards, and when Mikela was puzzled by the circular story structure of an Aboriginal traditional tale, expecting the definite "happily ever after" ending of Western tales. A mismatch can stem from a lack of knowledge about specific contexts and events, such as a Japanese graduate student who was unfamiliar with the Japanese occupation of Korea until reading When My Name Was Keoko (2012) by Linda Sue Park and undergraduate students who read Joelle Stolz's The Shadows of Ghadames (2006), set in late 1800s Libya, and assumed it was a modernday portrayal.

Cultural mismatches can lead readers to feel that they are unable to connect with characters, and so either reject the book as possible or feel pity and superiority. A group of undergraduates in my global citizenship class responded to Patricia McCormick's Sold (2008), about a thirteen-year-old girl from Nepal who is sold into sexual slavery by her father, with 
comments of pity and a sense of superiority that they live in the United States, where they thought this would never happen.

Choo argues that the purpose of global literature is responsible engagement and that educators have overemphasized both connection and reading for personal pleasure (Reading 141). She believes that readers should engage with a book out of a sense of responsibility to others and with the recognition that reading may be intellectually discomforting. The primary purpose of reading global literature is not to make personal connections or to feel pleasure, but to become more conscious and committed to others. Choo is not arguing against reading for enjoyment or connection; instead, she believes this expectation can be problematic and interfere with developing intercultural understanding. My question to readers is thus not "Did you like the book?" but "What are you thinking?"

Readers are also responsible not to position their culture as the norm, from which they judge characters as exotic or as exactly the same as themselves. Readers exoticize when they view others as strange or different, where difference is a negative term to mean "you are not the same as or equal to me; I am not different, but you sure are.” Readers universalize when they believe that "we are all the same on the inside." This emphasis on commonality and rejection of difference comes from a stance of colorblindness, which provides an avenue for readers to avoid hard conversations about racism.

As readers, we are responsible for examining and owning our cultural locations and recognizing when we are reading a book through our location and thus judging the actions of characters from that positionality. My cultural location makes books such as Never Fall Down (2012) by Patricia McCormick difficult because of the book's focus on a child soldier and forced killing. When reading this book, I have to make a conscious decision to step back from my 
location and not judge the character's actions. Jessica Mantei and Lisa Kervin report that children in Sydney read Mirror from their own cultural locations in judging the family from Morocco, stating, "They don't have what we have" and "We've got everything and they have nothing" (188).

We also need to be aware when global books are generic with a universal theme, but without a cultural location in a specific place and time. Culturally generic books, such as the Swiss Rainbow Fish (1999) by Marcus Phister, are easy to translate across cultural boundaries because they do not challenge readers to move beyond their own cultural views. In contrast, a culturally specific book has both universal themes and a specific cultural setting in the text or illustrations. New Shoes for Helen (2011) by Ifeoma Onyefulu reflects a young child's universal enjoyment of getting new shoes, with illustrations indicating this shopping expedition is occurring in an Ethiopian market. Culturally specific books challenge readers to immerse themselves in another culture and way of thinking, while still providing universal connections. These books, however, can be more difficult for readers to understand and so may have smaller market appeal, such as occurred with Nahoko Uehushi's Moribito (2009), a translated Japanese fantasy, in the United States. Without support by teachers in classrooms, these books may not find readers.

The social responsibility of readers thus involves identifying and reflecting on the cultural locations and biases we bring to a book, and becoming aware of how our cultural locations do and do not connect with the cultural location of that book. Our task is a willingness to be open and to learn from another's life and experiences. We read for what we might learn and out of commitment to others, not just for connection. 


\section{Social Responsibility of Educators}

The responsibilities of readers and bookmakers inform the work of educators in developing their awareness of the potentials and dangers specific books hold in relation to the cultural locations of readers. The responsibilities of educators center on creating learning contexts that encourage dialogic inquiry around literature. These contexts ensure that readers never read a book alone, but instead read alongside other books, and engage in dialogue with each other to develop a critical lens to bring to reading events.

As an educator, I have observed the danger of having students read a global book alone. Unless they bring life experiences from that culture, their tendency is to see that book as representative of an entire global culture, so I ask students to read a global book along with other books or materials. Through intertextuality, students consider how texts play off of each other to create a context within which to read a book. For example, I found that undergraduate students knew little about Stalin and so had difficulty understanding Breaking Stalin's Nose (2011) by Eugene Yelchin until I paired that book with a short biography of Stalin.

Paired books, in which readers read two books that are set in some kind of opposition to each other, has been a particularly effective strategy. We have paired a local book with a global book with similar themes (e.g., Something Beautiful by Sharon Wyeth with Sami and the Time of Troubles by Florence Heide); two global books with similar themes (e.g., Bronze and Sunflower by Cao Wenxuan with The War That Saved My Life by Kimberly B. Bradley); two books depicting the same event from different viewpoints (e.g. When My Name Was Keoko with So Far from the Bamboo Grove by Yoko Watkins); a fiction book with an informational book, as in the Stalin example; and a classic text with a global book (e.g., The Great Gatsby by F. Scott Fitzgerald with The Summer Prince by Alaya Johnson). 
Many examples of paired books can be found on the Worlds of Words website, as part of the Global Reading Lists (wowlit.org). This site also has examples of global culture text sets—sets of fifteen to twenty picturebooks that reflect diverse experiences within a specific global culture, such as India, Finland, South Korea, or Mexico. These sets can be read with younger children over time or serve as background reading and browsing for a group of older students before they read novels from these cultures. Another type of text set is thematic sets around global themes and issues (e.g., refugees, death, human rights), where the books reflect a wide range of cultures with differing perspectives on those themes. Experiences with paired books and text sets help readers create a sense of connection across global cultures, along with a realization of uniqueness and difference between cultures.

Another social responsibility of educators is to provide a context in which readers can position themselves and the book, learning to question why they have a particular response and exploring additional materials to place the book within a broader context. A teacher showed photographs of urban Casablanca and the desert Outback before eight-year-olds interacted with Mirror (Aziz 187). They quickly took on a critical stance toward the book, recognizing and questioning the misrepresentations. In my global course, I ask undergraduates to select something of interest to research on the Internet for each global book they are reading. They share this research as part of their literature discussions. In the small group reading Sold, the expressions of pity and superiority shifted when a student shared her research on sex trafficking of girls in Tucson, Arizona, bringing the issue into their own location and leading to a more thoughtful discussion of the book.

Another useful strategy is asking students to research the background of bookmakers to explore their cultural locations in relation to the book's context. Undergraduate students reading 
Homeless Bird (2001) by Gloria Whelan and Keeping Corner (2007) by Kashmira Sheth, on child widows in India, shifted in their responses once they realized that Gloria Whelan had only researched online, while Kashmira Sheth was born in India and based the book on her aunt's experiences. The juxtaposition of reading both books also brought the realization that Whelan's book read like a fairy tale without a specific setting, while Sheth immersed them in the sights and sounds of India.

When students read books alongside each other and within broader contexts, they are more likely to respond from a perspective of empathy, rather than sympathy, as occurred with the group discussing Sold. Brené Brown argues that empathy highlights understanding the emotions of someone else and connecting to something within yourself that knows that feeling. Too often, readers are encouraged to connect to experiences that differ radically from their lives rather than to underlying emotions. Considering when they have felt loneliness or fear and connecting at a deeper emotional level can fuel a sense of connection with characters. In contrast, sympathy involves feeling bad for someone and wanting to make things better, and so comes from a perspective of superiority that drives disconnection.

Another aspect of social responsibility for educators is creating contexts that encourage dialogue between readers and between readers and bookmakers. Dialogue involves readers walking alongside and talking with, not at, others and being willing to wrestle with issues instead of walking on the surface of those issues. Dialogue combines critique and inquiry, as readers pose questions, challenge the status quo, and collaboratively consider multiple viewpoints on an issue. Freire argues that dialogue provides the most potential for transformation and change by combining love, humility, faith in others, hope, and critical thinking (72). 
Dialogue strategies provide a means of encouraging readers to reflect deeply on a book in order to find issues they consider significant, instead of being guided by what a teacher has already identified. Strategies such as Save the Last Word for Me, Sketch to Stretch, Consensus Boards, and Webbing encourage readers to linger and reflect on their responses and consider multiple interpretations through dialogue with other readers (Short and Harste). Sketch to Stretch asks readers to sketch the meaning of a book and so encourages symbolic thinking. In Save the Last Word, each reader selects a significant quote to read to the small group. Group members talk about why they think the quote is significant, while the original selector remains silent. The reader then has the "last word" to talk about the reason for selecting the quote, encouraging the consideration of multiple interpretations.

\section{Conclusion}

Those of us committed to the potentials of global literature do so from the belief that thoughtful interactions with these books encourage readers to take a stance of openness to multiple ways of thinking and being in the world, as well as to differences as resources for our shared humanity. This stance also invites our social responsibility as bookmakers, readers, and educators to work together to create a better and more just world.

Those potentials, however, can only be realized if we acknowledge that opening a global book can actually close a mind and leave the world unchanged. The dangers of reading globally need constant attention, or our work to promote intercultural understanding will remain elusive. By taking a stance of social responsibility, we increase the likelihood that interactions with global literature will instead open minds and create the possibility of changing the world. 


\section{Works Cited}

\section{Children's Books}

Baker, Jeanne. Mirror. Candlewick, 2010.

Bradley, Kimberly B. The War That Saved My Life. Dial, 2015.

Fitzgerald, F. Scott. The Great Gatsby. Wisehouse, 2016.

Gray, Nigel. A Country Far Away. Illustrated by Philippe Dupasquier. Vivid, 2012.

Heide, Florence. Sami and the Time of Troubles. Illustrated by Ted Lewin. Clarion, 1992.

Johnson, Alaya. The Summer Prince. Scholastic, 2013.

Kostecki-Shaw, Jenny Sue. Same, Same but Different. Holt, 2011.

McAlister, Caroline. Holy Molé! Illustrated by Stefan Czernecki. August House, 2006.

McCormick, Patricia. Never Fall Down. HarperCollins, 2012.

---. Sold. Hyperion, 2008.

Onyefulu, Ifeoma. New Shoes for Helen. Frances Lincoln, 2011.

Park, Linda Sue. When My Name Was Keoko. HMH, 2012.

Phister, Marcus. Rainbow Fish. Translated by Alison James. North South, 1999.

Recorvitz, Helen. Yoon and the Jade Bracelet. Illustrated by Gabi Swiatkowska. Farrar, 2008.

Sheth, Kashmira. Keeping Corner. Hyperion, 2007.

Stolz, Joelle. The Shadows of Ghadames. Translated by Catherine Temerson. Delacorte, 2006.

Uehushi, Nahoko. Moribito. Translated by Cathy Hirano. Scholastic, 2009.

Watkins, Yoko. So Far from the Bamboo Grove. HarperCollins, 2008.

Wenxuan, Cao. Bronze and Sunflower. Translated by Helen Wang. Candlewick, 2017.

Whelan, Gloria. Homeless Bird. HarperCollins, 2001.

Wyeth, Sharon. Something Beautiful. Illustrated by Chris Soenpiet. Doubleday, 1998. 
Yelchin, Eugene. Breaking Stalin's Nose. Holt, 2011.

\section{Secondary Sources}

Adichie, Chimamanda. "The Dangers of a Single Story.” TED Talk, 2009, www.ted.com/talks/chimamanda_adichie_the_danger_of_a_single_story.

Aziz, Seemi. "Encouraging Cultural Awareness through an Exploration of Muslim Cultures." Teaching Globally: Reading the World through Literature, edited by Kathy G. Short et al., Stenhouse, 2016, pp. 179-96.

Bishop, Rudine Sims. "Mirrors, Windows, and Sliding Glass Doors.” Perspectives, vol. 1, no. 3, 1990, pp. ix-xi.

Brown, Brené. Dare to Lead. Random, 2018.

Chandler, David. Strategic Corporate Social Responsibility. Sage, 2016.

Choo, Suzanne. "Globalizing Literature Pedagogy: Applying Cosmopolitan Ethical Criticism to the Teaching of Literature." Harvard Educational Review, vol. 86, no. 3, Fall 2017, pp. $335-56$.

---. Reading the World, the Globe, and the Cosmos. Peter Lang, 2013.

Fox, Dana, and Short, Kathy G. Stories Matter: The Complexity of Cultural Authenticity in Children's Literature. National Council of Teachers of English, 2003.

Freire, Paulo. Pedagogy of the Oppressed. Continuum, 1970.

Johnson, Holly. “The Social Responsibility of the Reader.” Teaching Globally: Reading the World through Literature, edited by Kathy G. Short et al., Stenhouse, 2016, pp. 25-42. Mantei, Jessica, and Kervin, Lisa. "Examining the Interpretations Children Share from Their Reading." Australian Journal of Language and Literacy, vol. 38, no. 3, 2015, pp. 183-92. 
Rosen, Harold. Stories and Meanings. NATE, 1986.

Rosenblatt, Louise. Literature as Exploration. Modern Language Association, 1938.

Short, Kathy G. "Story as World Making." Language Arts, vol. 90, no. 1, Sept. 2012, pp. 9-17.

---. "What's Trending in Children's Literature and Why It Matters." Language Arts, vol. 95, no.

5, May 2018, pp. 287-98.

Short, Kathy G., and Harste, Jerome. Creating Classrooms for Authors and Inquirers. Stenhouse, 1996.

Kathy G. Short is a professor in the College of Education at the University of Arizona in the U.S. with a focus on inquiry, dialogue, and global literature. She is Director of Worlds of Words, a center on global literacies and literatures (wowlit.org). Her most recent edited books include Teaching Globally: Reading the World through Literature, Critical Content Analysis of Children's and Young Adult Literature, and Critical Content Analysis of Visual Images in Books for Young People. She is a past President of NCTE and USBBY. 